\title{
Analyzing Short Circuit Forces in Transformer for Double Layer Helical LV Winding using FEM
}

\author{
Deepika Bhalla ${ }^{\mathrm{a}}$, Raj Kumar Bansal ${ }^{\mathrm{b}}$, and Hari Om Gupta ${ }^{\mathrm{c}, *}$ \\ ${ }^{a} I K$ Gujral Punjab Technical University, Kapurthala, Punjab, 144 603, India \\ ${ }^{b}$ Guru Kashi University, Talwandi sabo, Punjab, 151 302, India \\ ${ }^{c} J$. P. Institute of Information Technology, Sector 128, 201 314, India
}

\begin{abstract}
In medium and high capacity transformers where current rating is high and the number of turns is low, the low voltage (LV) winding is generally of the helical type. These helical windings have very large magnitudes of electromagnetic forces during a short circuit. This is due to the inherent asymmetry of helical structure. The objective of this work is to use the finite element method to compute the radial and axial components of short circuit forces and identify areas of high stresses in the windings. This can be used to find the likely reason of transformer failure during a short circuit. For this work, a 3-phase power distribution transformer of $11 \mathrm{kV} / 433 \mathrm{~V}, 630 \mathrm{kVA}$ rating is considered. The effect on short circuit forces of the tapping in the center of HV winding is also studied.
\end{abstract}

Keywords: double layer helical winding; electromagnetic forces; finite element method; power transformer; short circuit forces

(Submitted on May 9, 2017; First revised on July 30, 2017; Second revised on January 11, 2018; Accepted on January 14, 2018)

(C) 2018 Totem Publisher, Inc. All rights reserved.

\section{Introduction}

The transformer is a critical component of a power system, and reliability of the system depends on its proper operation and design. The mechanical stresses that occur due to short circuit can damage the insulation and deform the windings and core, thus causing transformer failure that results in costly outages. Proper design of windings and insulation can reduce the inservice failure of the transformer. The knowledge of the magnitude of short circuit forces helps the design engineer manage the mechanical stress. If the design is such that the ability to withstand short circuit forces is poor, then it would result in transformer failure during testing or soon after installation. For a design, if the region where forces would act during short circuit is known, then proper mechanical support and insulation can be provided to prevent failure. The failure of transformer could be due to the radial or axial component of the electromagnetic force produced during short circuit. Bucking of low voltage (LV) winding and stretching of high voltage (HV) winding are caused due to radial force, while conductor tilting and axial bending between spacers are due to axial force.

During physical inspection of transformers that have failed due to passing of short circuit current, it is observed that the yoke gets separated from the limbs, and at times, the insulation in the end turns is damaged. The start and end of a transformer winding is connected to the bushings at the top of the tank; very often it is observed that the connection at this point breaks. This is due to repetitive mechanical stresses that cause the forces to set the winding into vibrations and creep sets [3].

Failure of the transformer that involves the core and the windings can be reduced by proper design of insulation, configuration of winding, lead configuration, clearances and short circuit capacity. However, finding the best design for a rating transformer (to prevent failure) is a challenging task because there is no standard that keeps a record of failure due to seed defect in the design and its analysis.

Accurate modelling of the problems with complex geometry and composition can be performed by finite element method (FEM); it can be used to estimate the electromagnetic forces for mechanical stresses and heat flow for thermal stresses. Lorentz

\footnotetext{
* Corresponding author.

E-mail address: deepika.bhalla89@gmail.com
} 
forces and the Maxwell stress tensor are the two methods used to estimate electromagnetic forces. The electromagnetic flux and the winding circulating current create a force called the Lorentz force. The Maxwell stress tensor is obtained by replacing the current density with the magnetic field [6].

FEM has been used to compute the electromagnetic forces of a distribution transformer [11]. It has been found that the forces computed by 3D and simplified 2D asymmetric FEM methods agree with each other: the total forces in front view and end view are quite close, and the forces in the window region are larger than the forces along the circumference of the winding [10]. Safety factors for radial and axial forces during short circuit in a power transformer have been proposed using the results of FEM [2]. FEM was for the first time applied to a helical winding to study the effect of transposing the windings [5]. The circumferential displacement during short circuit of helical winding was studied and it was found that as the helical angle increases, the circumferential forces increase and maximum stresses occur at the ends of the winding [13]. Transient electromagnetic forces in radial and axial directions induce critical mechanical stress in the transformer windings. This has been analyzed using FEM [1]. 2D FEM was used for investigation of effect of short-circuit current on electromagnetic force for an oil-immersed power transformer, along with transient dynamic response of windings deformation [14]. Short circuit forces in transformer have been analyzed for LV winding of single/one-layer helical winding using FEM; analysis concluded that the nature of the axial forces is such that it can cause spiraling [4]. When a three-phase short circuit occurs in a core type transformer, there is a heavy concentration of electromagnetic fields in the window region; maximum failures occur in this region. Higher forces are exerted in the windings on the central limb, and there is a considerable variation of forces along the winding circumference [9]. The winding deformations caused due to short circuit forces are essential for design review [12]. The forces of interaction between different arrangements of winding depends upon the relative height of the two windings. Work on use of FEM for computing radial and axial forces in helical winding of a single layer type has been done [4]. Work on use of FEM for computing radial and axial forces in helical winding of double/two- layer type and the effect of tapping has not been done.

The electromagnetic forces developed during short circuit along the circumference of a double/two-layer helical LV winding and cross-over type HV winding are computed using FEM, so as to study the variation in forces due to the inherent asymmetry of helical structure. The forces in the LV and HV windings are analyzed separately to study the possible impact on other parts/components. Parallel study of asymmetry due to $10 \%$ center tapping of the HV winding is also carried out. For this study, the cross section of windings is used and unit depth in $\mathrm{mm}$ is taken for modelling. The forces are calculated on current driven magnetics, 2D planer FEM Magnetic version 4.2 [6]. The Dirichlet boundaries are taken and windings on the central limb are only energized.

\section{Short Circuit Current and Forces}

When a transformer is connected to a system of infinite fault capacity, the worst condition that can occur in practice is the current corresponding to the first peak of a 3-phase short circuit flowing through the winding. The severity of the fault depends upon the parameters of the system, and it is limited by the arc resistance and system impedance. The maximum value of short circuit current $I_{S}$ (amps) is given by the expression:

$$
I_{s}=\frac{\sqrt{2} \times K \times k V A \times 10^{3}}{\sqrt{3} \times V_{l} \times e_{z}}
$$

where, $V_{1}$ is the primary voltage, $e_{z}$ is fractional per unit impedance voltage and $K$ is the asymmetry factor. The value of $\sqrt{2} \times K$ is calculated as per IEC standard 60076 [8]. For accuracy of the forces the value of impedance corresponding to the tapping position needs to be considered; hence, the tapping position decides the impedance voltage $\mathrm{e}_{\mathrm{z}}$ [7].

The interaction of the current with the flux produces electromagnetic forces. The mechanical stresses due to electromagnetic forces during short circuit can be large enough to cause mechanical collapse of the winding, damage the cellulose insulation, and/or deform the clamping structure. Faults develop in components where mechanical stress occur and can lead to failure of the transformer. The mechanical stresses cannot be removed, but proper design can reduce them. A transformer must be designed to withstand mechanical stresses caused due to a three phase short circuit.

\section{Asymmetry in Winding}

\subsection{Tapping}

The HV winding are tapped for three reasons: to maintain the voltage within statutory limits, control the kilowatt and kilovar flow over a line interconnecting two generating stations, and/or to adjust the cyclic changes of load distribution. These 
may be provided at the phase end, at the neutral point or in the middle of the phases. Magnetic asymmetry due to tapping cause unbalanced axial forces under fault conditions. The windings need to be arranged such that they limit the unbalance due to tapping. In practice, this unbalance is compensated by thinning the inner (LV) winding.

\subsection{Helical Winding}

Helical winding is spiral in shape and is used for the LV side. It carries high current and has less number of turns. The asymmetry caused by helical winding depends upon the helical angle. As the helix coils, it creates asymmetry along the circumference. The helical angle $(\alpha)$ of the winding is calculated by:

$$
\alpha=\tan ^{-1}\left[\frac{p}{\pi D_{m}}\right]
$$

where the mean diameter of the winding $\left(D_{m}\right)$ and pitch $(p)$ is equal to the height of the conductor (along with insulation) and oil ducts. The conductor is made up of many parallel strips that have a rectangular section and are paper covered. In power distribution transformers, the helical winding may be of single layer, double layer, or multiple layer type.

A double layer helical winding has two layers and the turn in each layer has one or more than one parallel strip. The turns are wound along a helical line. The first layer forms the outer/front coil and the second layer forms the inner/back coil. The conductor passes from outer layer to the inner layer at the bottom of the winding. Both the start and finish of the winding are at the top. The forces along the circumference of both HV winding and LV winding change. This is because the relative location of LV with respect to HV winding changes along the circumference. The outer and inner layer of LV winding attract each other as they carry current in the same direction.

\section{Design and Modeling}

The study of short circuit forces is carried out on an $11 \mathrm{kV} / 433 \mathrm{~V}, 630 \mathrm{kVA}$ power distribution transformer; the specifications are given in Table 1. The dimensions and other design parameters of the core and are given in Table 2.

Table 1. Specifications of 11kV/433V, 630kVA, 3 phase power distribution transformer windings
\begin{tabular}{|l|c|c|}
\hline \multicolumn{1}{|c|}{ Parameters } & LV winding & HV Winding [4] \\
\hline Type of coil & double layer-helical & cross-over \\
\hline Inter phase connections & Delta & Star \\
\hline No of coils per phase & 1 & 2 \\
\hline Conductor size (bare) & $10.02 X 4.70 X 6$ & Diameter: 2.85 \\
\hline Conductor size covered & $10.42 X 5.10$ & 3.150 \\
\hline Conductor placement & $3 \mathrm{WX} 2 \mathrm{D}$ & - \\
\hline Inner diameter of coil $(\mathrm{mm})$ & 207 & 275.5 \\
\hline Axial length of coil $(\mathrm{mm})$ & 398 & 398 \\
\hline No of turns per phase & 23 & 1062 \\
\hline No of turns per coil & 23 & 531 \\
\hline No of turns per layer & 11.50 & 59 \\
\hline No of layers & 2 & 9 \\
\hline Outside diameter of coil $(\mathrm{mm})$ & 254.5 & 339.5 \\
\hline Yoke clearance & 21.5 & 13 \\
\hline
\end{tabular}

As shown in Figure 1, the inner layer of LV winding has turns 1 - 12 and the outer layer has turns $13-24$. The turn-1 of the inner layer and turn-24 of the outer layer are connected to the line terminal through the bushings. Turn-1 and turn-24 are at the top, and turn-12 and turn-13 are at the bottom of the winding.

When there is no asymmetry, the LV winding cross section has a height of $398 \mathrm{~mm}$ and width of $23.75 \mathrm{~mm}$, and the $\mathrm{HV}$ winding has a height of $398 \mathrm{~mm}$ and width of $32 \mathrm{~mm}$. The axial and radial forces $(\mathrm{N})$ in each layer of LV winding is calculated in $\mathrm{z}$-direction (for unit depth in $\mathrm{mm}$ ) for a vertical section of the winding that is a rectangular bar of $398 \mathrm{~mm} \mathrm{X} 11.875 \mathrm{~mm}$, and the space between the inner and outer layer is ignored. For HV winding the rectangular bar/section is of $398 \mathrm{~mm} \mathrm{X} 32 \mathrm{~mm}$. The radial force and axial force in per unit depth in these two rectangular bars are computed. 
Table 2. Design parameters and dimensions of core for $11 \mathrm{kV} / 433 \mathrm{~V}, 630 \mathrm{kVA}, 3$ phase power distribution transformers

\begin{tabular}{|l|c|}
\hline \multicolumn{1}{|c|}{ Parameter } & Specifications \\
\hline Core material & M4 \\
\hline Stacking factor & 0.97 \\
\hline Maximum flux density & $1.6800 \mathrm{~T}$ \\
\hline Core diameter & $200 \mathrm{~mm}$ \\
\hline Yoke height & $195 \mathrm{~mm}$ \\
\hline Window height & $440 \mathrm{~mm}$ \\
\hline Leg center & $350 \mathrm{~mm}$ \\
\hline
\end{tabular}

The short circuit forces $(\mathrm{N})$ are found in $\mathrm{z}$-direction (per unit depth) of the conductor, which are separate for the inner and outer layers. To study the change in magnitude of forces along the circumference in each section, the position of HV winding is kept fixed, and LV winding is positioned at a vertical shift equal to pitch/12 along the circumference.
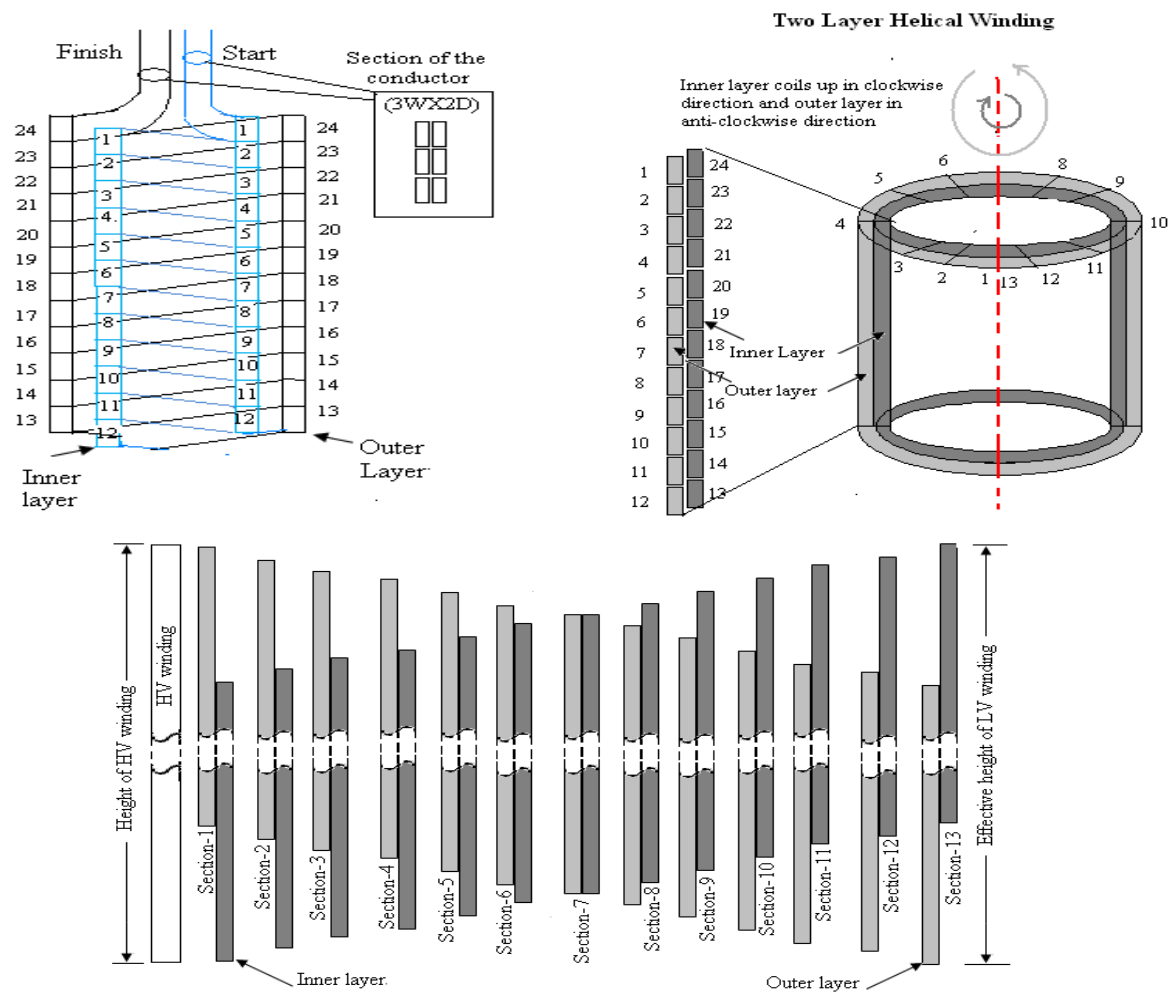

Figure 1. Details of double layer helical winding (figure not to scale).

The force in each sector is the average force between two adjacent sections multiplied by $\left(\pi \mathrm{D}_{\mathrm{m}} / 12\right)$. The sum of the axial forces in the twelve sectors of both the layers is taken together to find the net axial force in LV winding [4]. The negative sign of radial force indicates its direction towards the core, and the positive sign indicates its direction towards the tank. The negative sign of axial force indicates its direction to be downwards towards the bottom of the winding, and the positive sign indicates the direction to be upwards towards the top of the winding.

The average value of the axial force of thirteen sections is multiplied with the mean circumference of the winding to find the net axial force in $\mathrm{HV}$ winding. To study the effect of tapping, $10 \%$ winding is removed from the middle of the HV winding. The simulation parameters are identical to that used in a similar study for a same rating transformer having a single/one-layer helical type as the LV winding [4].

\section{Short Circuit Forces in LV Winding}

\subsection{No Asymmetry}

The no asymmetry condition is in section 7. Figure 2 shows the short circuit flux density plot on simulation when $10 \%$ of $\mathrm{HV}$ winding is center tapped and the central limb is energized. 


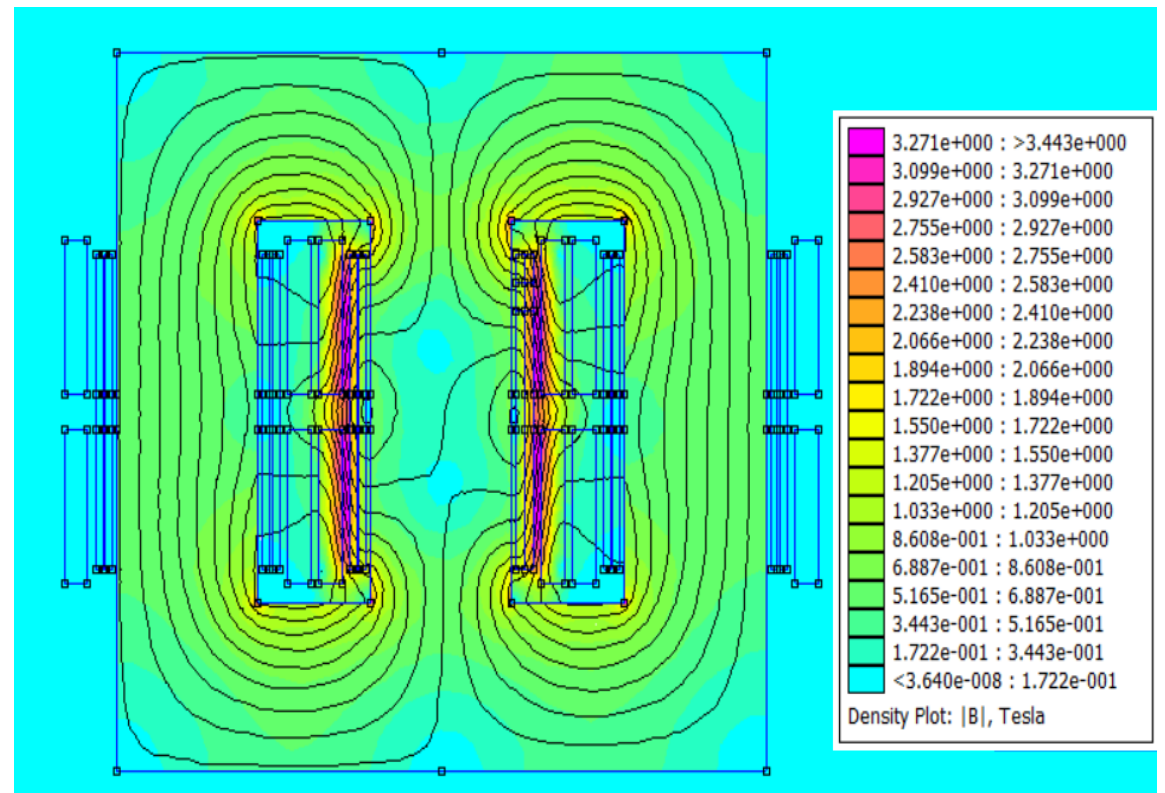

Figure 2. Flux density plot of section 7 of the transformer windings (no asymmetry condition)

The short circuit forces per unit circumferential depth $(\mathrm{mm})$ when there exists no asymmetry (either due to difference in the height of LV \& HV windings or due to tapping in HV winding) is given in Table 3.

Table 3. Short circuit forces exerted per unit circumferential depth when there exists no asymmetry

\begin{tabular}{|c|c|c|c|}
\hline \multirow{2}{*}{\multicolumn{2}{|c|}{ Winding }} & \multicolumn{2}{|c|}{ Force per unit circumferential depth $(\mathrm{N})$} \\
\hline & & Radial & Axial \\
\hline \multirow{2}{*}{ LV } & inner layer & -155.11 & -15.13 \\
\hline & outer layer & -481.37 & -15.10 \\
\hline \multicolumn{2}{|l|}{$\mathrm{HV}$} & 729.29 & 29.13 \\
\hline
\end{tabular}

Radial force: The direction of radial force in LV winding is towards the core, and in the HV winding it is towards the tank. Radial force experienced by the outer layer of LV winding that is near the gap is $75 \%$ of the total force. This outer layer that is closer to the gap is more stressed because it lies in the region where the leakage flux is higher.

Axial force: The direction of axial force in LV winding is downwards, and in the HV winding it is upwards. The axial force is equally shared between the inner and outer layer of the LV winding.

\subsection{Asymmetry due to center tapping}

Table 4 gives the value of short circuit forces exerted in different parts of LV winding; for tapped and untapped winding, the radial and axial forces are calculated separately.

Radial force: $10 \%$ center tapping in HV winding results in negligible change of radial force in LV winding. Radial force experienced by end turn (turn-24) of the inner layer increases by $10.97 \%$, while that experienced by the end turn (turn-1) of the outer layer increases by only $1.11 \%$. The effect of force in end turn needs further investigation (beyond the scope of this paper).

Axial forces: The axial force in LV winding acts in the downward direction, towards the lower yoke, and there is a decrease of $7.05 \%$ due to tapping. The downward directed axial force experienced by the end turn (turn-24) of the inner layer decreases by $8.65 \%$, while that experienced by the outer layer decreases by $5.44 \%$ due to tapping.

\section{Short Circuit Forces in HV Winding}

Table 5 gives the short circuit electromagnetic forces of the HV winding. The radial force is directed towards the transformer tank. The axial force has a considerable magnitude and is directed towards the upper yoke. Due to tapping, the radial force decreases marginally by $2.17 \%$. The axial force reduces by $6.42 \%$ due to tapping. 
Table 4. Forces in LV winding and the end turns

\begin{tabular}{|c|c|c|c|}
\hline \multirow{2}{*}{ 苛 0} & \multirow{2}{*}{ Region } & \multicolumn{2}{|c|}{ Magnitude of force $(\mathrm{N})$ (per unit depth in $\mathrm{z}$-direction) } \\
\hline & & without tapping & with tapping \\
\hline \multirow{6}{*}{ 胥 } & Inner layer & -155.11 & -155.12 \\
\hline & End turn (turn-24) of inner layer, & -10.01 & -11.11 \\
\hline & End minus one turn (turn 23) of inner layer & -12.54 & -13.07 \\
\hline & Outer layer & -481.37 & -478.24 \\
\hline & End turn (turn-1) of outer layer & -33.16 & -33.53 \\
\hline & End minus one turn (turn 2) of outer layer & -38.54 & -39.07 \\
\hline \multirow{6}{*}{$\frac{\pi}{\frac{\pi}{x}}$} & Inner layer & -15.13 & -13.83 \\
\hline & End turn (turn-24) of inner layer, & -19.97 & -20.32 \\
\hline & End minus one turn (turn 23) of inner layer & -13.06 & -16.88 \\
\hline & Outer layer & -15.10 & -14.28 \\
\hline & End turn (turn-1) of outer layer & -18.09 & -19.02 \\
\hline & End minus one turn (turn 2) of outer layer & -11.94 & -15.55 \\
\hline
\end{tabular}

Table 5. Short circuit forces exerted in HV winding

\begin{tabular}{|l|c|c|}
\hline \multirow{2}{*}{ Force } & \multicolumn{2}{|c|}{ Magnitude of force (N) per unit depth (in z- direction) } \\
\cline { 2 - 3 } & without tapping & with tapping \\
\hline Radial & 729.29 & 713.45 \\
\hline Axial & 29.13 & 27.26 \\
\hline
\end{tabular}

\section{Flux distribution and forces along the circumference during short circuit}

Figure 3 gives the variation in lines of flux and flux density plot in the transformer for section 1, 3, 5, 7, 9,11, 13. The variation in lines of flux and flux density for without tapping can be seen in Figure 3 (a), and those with tapping can be seen in Figure 3 (b).

For section 7, when no asymmetry exists, the flux lines in the upper and lower half are identical. In double layer LV winding the relative position of the outer and inner layer is different along the circumference. Since maximum asymmetry is in section 1 and section 13, the flux lines are different in the upper and lower half of the winding.
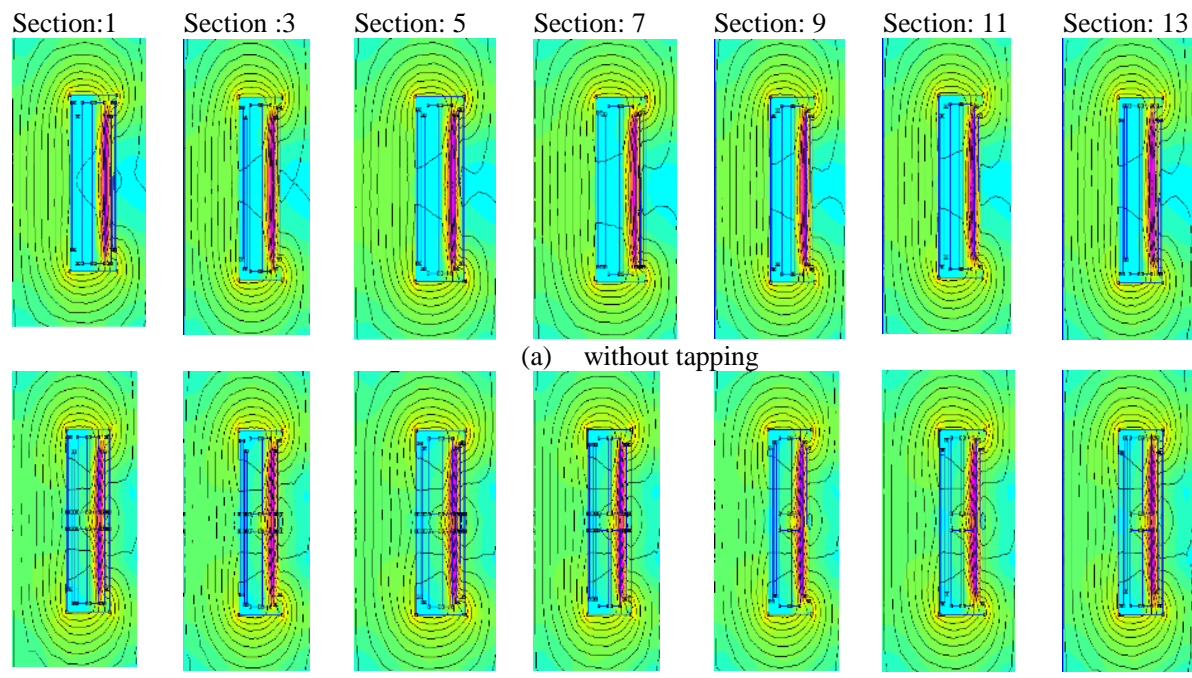

(b) with tapping

Figure 3. Variation of flux along the circumference

\subsection{LV winding}

Radial forces: Figure 4 shows the radial force exerted in 13 vertical sections along the LV winding circumference. The radial force developed has its direction towards the core and its magnitude increases from section- 1 to section- 7 and reduces back to a value close to that in section-1 as the helix coils up to section-13. The radial force magnitude is slightly more in the rear side of the transformer winding i.e. from section-3 to section- 11 .

Due to the presence of tapping, the radial force magnitude decreases marginally by $0.15 \%$. 


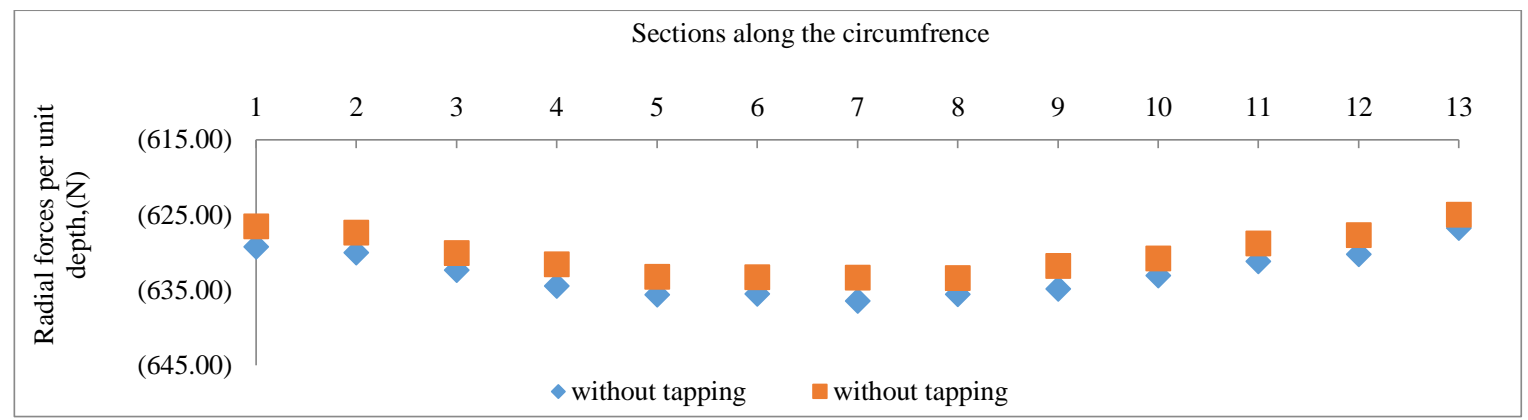

Figure 4. Radial force exerted (in 13 vertical sections) along the circumference of LV winding

Axial force: Figure 5 shows the axial forces exerted along circumference in inner and outer layer of LV winding. The axial force in turn-1 (start of inner layer) and turn-24 are outer winding of the range of $27 \mathrm{~N}-29 \mathrm{~N}$ per unit depth in the downward direction. This would be a type of cyclic load, and creep would set in. Figure 6 shows axial force exerted in the 13 vertical sections along the LV winding circumference; it is a nearly uniform downward directed force of $(-28 \mathrm{~N})$ per unit depth (z-direction). Axial forces in the LV winding have a negligible effect of $10 \%$ center tapping of HV winding.

Considering the only asymmetry to be $10 \%$ center tapping of the HV winding, the downward directed axial force reduces by $7 \%$. The effect on the inner layer is $23 \%$ more than that in the outer layer.

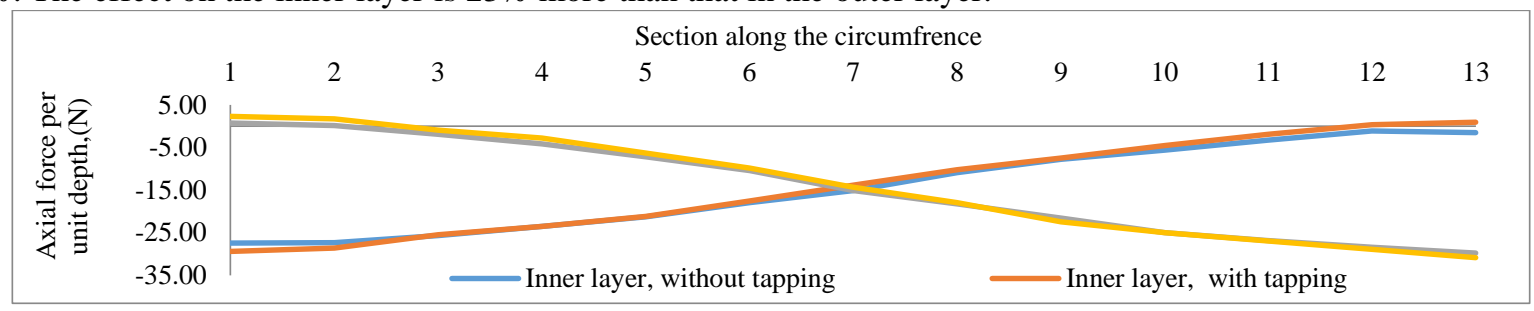

Figure 5. Axial forces exerted in inner and outer layer of the LV winding along circumference

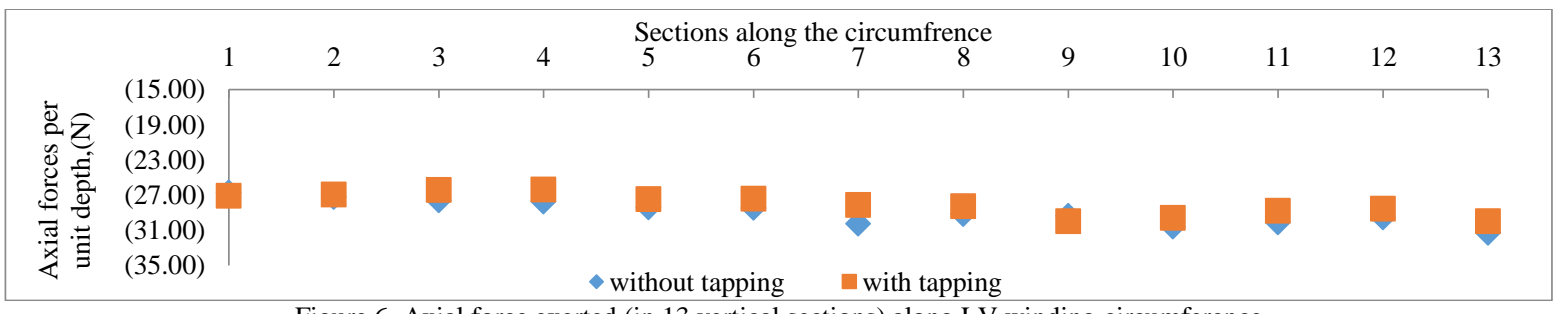

Figure 6. Axial force exerted (in 13 vertical sections) along LV winding circumference

\subsection{HV Winding}

Radial force: Radial force exerted (in 13 vertical sections) along the circumference of HV winding is shown in Figure 7 . The direction of the radial force in $\mathrm{HV}$ winding is towards the tanks and is of bursting nature.

Axial force: Axial force exerted (in 13 vertical sections) along the circumference of HV winding is shown in Figure 8. The force exerted is of uniform magnitude and directed towards the upper yoke. The magnitude per unit depth is $28 \mathrm{~N}$ without tapping and $26 \mathrm{~N}$ for tapping in HV winding. These forces are shown pictorially in Figure 9.

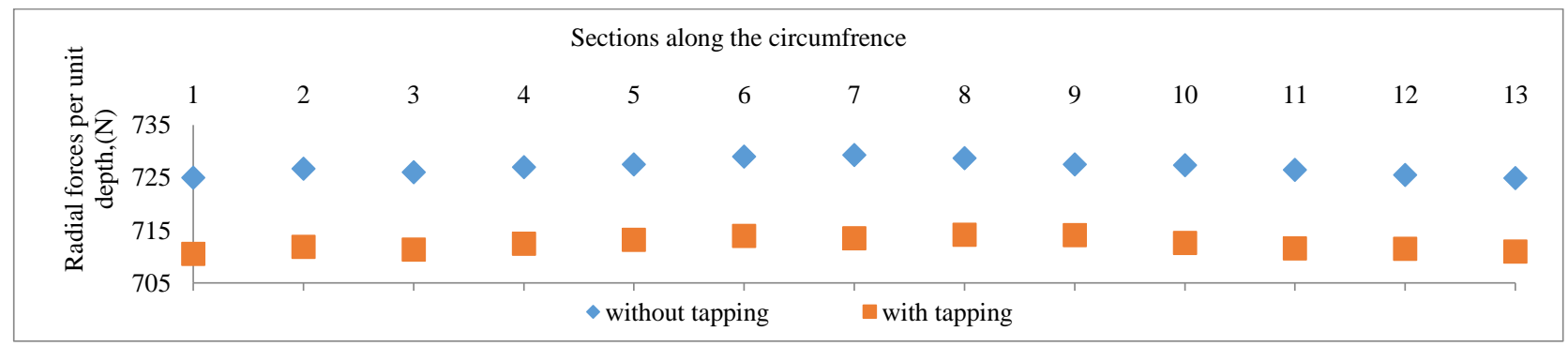

Figure 7. Radial force exerted (in 13 vertical sections) along HV winding circumference 


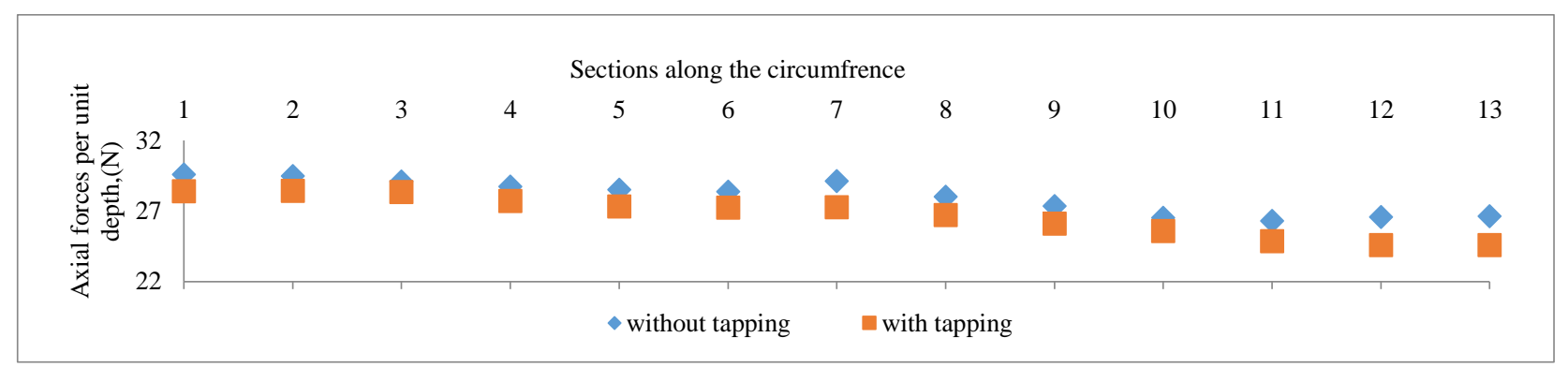

Figure 8. Axial force exerted (in 13 vertical sections) along LV winding circumfrence
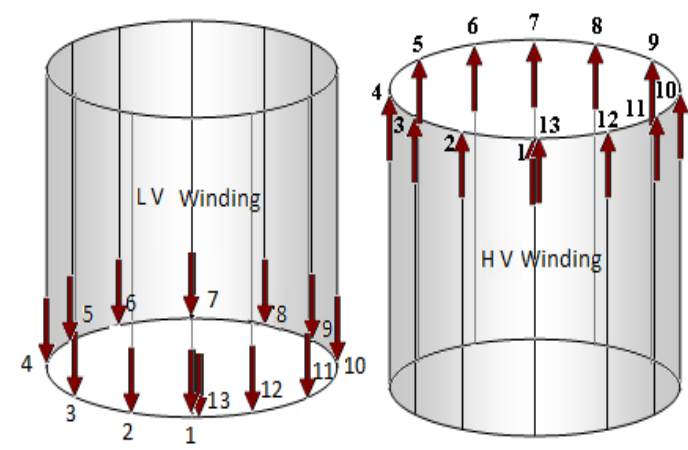

Figure 9. Pictorial representation of axial forces in LV and HV Windings

\subsection{Net Axial forces}

In the double layer $\mathrm{LV}$ winding the net axial force is $21 \mathrm{kN}$ and is directed towards the lower yoke. For center tapping of $\mathrm{HV}$ winding, the magnitude of downward directed net axial force in $\mathrm{LV}$ winding reduces by $3.53 \%$. The net axial force is $27 \mathrm{kN}$ in the $\mathrm{HV}$ winding, and its direction is towards the upper yoke. For the tapped HV winding, the net axial force reduces by $5.18 \%$.

\section{Conclusions}

The axial force developed in both the LV and HV windings are nearly uniform along the circumference. When the design of the provision to withstand forces is not adequate, the axial short circuit force in double layer LV winding can crush the end ring and damage the insulation of the end turns at the bottom end of this winding. Considering the outer and inner layer separately, it is observed that the front end where the winding starts and ends the downward directed axial force has maximum magnitude, it is in this region the conductor tilting and axial bending between radial spacers is more likely to occur. The HV winding is wire and impregnated, hence, it behaves as a solid mass; the magnitude of the axial force may separate the upper yoke from the limbs. The radial stresses may lead to buckling of the LV winding and the telescoping of the conductors of the $\mathrm{HV}$. Once the magnitude of short circuit force along the circumference is known, then components with adequate restraining force can be incorporated in these areas of higher stress at the time of design. For future scope, the asymmetry due to difference in the height of the windings can be studied to find the optimum height of the winding when the short circuit stresses are least.

\section{References}

1. H. -M. Ahn, J. -Y. Lee, J. -K. Kim, S. -Y. Jung, and S. -C. Hahn, "Finite-Element Analysis of Short-Circuit Electromagnetic Force in Power Transformer," IEEE Transactions on Industry Applications, vol. 47, no. 3, pp. 1267 - 1272, 2011

2. A. Bakshi, and S. V. Kulkarni, "Towards Short-Circuit Proof Design of Power Transformers" International Journal for Computation and Mathematics in Electrical and Electronics Engineering, vol. 31, no. 2, pp. 692-702, 2012

3. N. K. Beniwal, D. K. Dwivedi, H. O. Gupta, "Creep life assessment of distribution transformer," Engineering failure Analysis, pp. 1077-1085, 2010 (DOI: 10.1016/j.engfailanal.2010.01.001)].

4. D. Bhalla, R. K. Bansal, and H. O. Gupta, "Analysing Short Circuit Forces in Transformer with Single Layer Helical LV Winding using FEM," Proceedings of 2nd International Conference on Recent Advances in Engineering \& Computational Sciences (RAECS), (DOI:10.1109/RAECS.2015.7453274)

5. Y. Chao, X. Wang, and X. Dexin, "Positive and Contrary-Direction Transposition of Double Helical Winding in Power Distribution Transformer," Proceedings of 5th International Conference on Electrical Machines and Systems, pp. 198-200, 2001.

6. M. David, "Finite Element Method Magnetics," Version 4.2, User's Manual, 2010

7. J. H. Harlow, Electrical Power \& Transformer Engineering, CRC Press. 
8. IEC standard 60076 Power Transformers

9. S. V. Kulkarni and S. A. Khaparde, "Transformer Engineering: Design and Practice," New York: Marcel Dekker, May 2004.

10. G. B. Kumbhar, and S. V. Kulkarni, "Analysis of Short-Circuit Performance of Split-Winding Transformer using Coupled Field-Circuit Approach,” IEEE Transactions on Power Delivery, vol. 22, no, 2, pp. 936-942, 2007

11. M. A. Sanz-Bobi, L. Rouco, R. Palacios, L. Flores, and P. Cirujano, "A Tool for the Assessment of Electromagnetic forces in Power Distribution Transformers," Journal of Energy and Power Engineering, vol. 5, no 10, pp. 972-977, 2011.

12. R. Smeets, "Short-circuit withstand capability of power transformers-Part I", Transformers Magazine, vol. 4, no.2, http://www.transformers-magazine.com, April 2017

13. X. Wang, S. Yu, Q. Zhao, S. Wang, R. Tang, and X. Yuan, "Effect of Helical Angle of Winding in Large Power Transformer," in Proceedings of International Conference on Electrical Machines and Systems, pp. 355-357, 2003

14. H. Zhang, B. Yang, W. Xu, S. Wang, G. Wang, and J. Zhang, "Dynamic Deformation Analysis of Power Transformer Windings in Short-Circuit Fault by FEM," IEEE Transactions on Applied Superconductivity, vol. 24, no. 3, June 2014 (DOI: 10.1109/TASC.2013.2285335) 